\title{
What triggers causal attributions? The impact of valence and subjective probability
}

\author{
GERD BOHNER and HERBERT BLESS \\ Universität Mannheim, FRG \\ NORBERT SCHWARZ \\ Zentrum für Umfragen, \\ Methoden und Analysen, \\ ZUMA E.V., \\ Mannheim, FRG \\ and \\ FRITZ STRACK \\ Universität Mannheim, FRG
}

\section{Abstract}

Various field studies and experimental simulations demonstrated that causal reasoning increases after unexpected as well as after unpleasant events. However, unpleasant events are seen as less likely than pleasant ones in everyday life. Accordingly, the subjective probability of the event and its hedonic quality were naturally confounded in these studies. To isolate the contribution of both determinants, the subjective probability and the valence of an event were independently manipulated in a laboratory experiment. Subjects completed an ostensible 'professional skills test' and received either success or failure feedback in relation to a criterion set by the experimenter. The subjective probability of success was varied by informing subjects about the distribution of success and failure in a comparable population (either 23 per cent or 77 per cent were said to meet the criterion). The results indicate a pronounced valence effect: The intensity of causal reasoning and the number of possible reasons reported for the outcome was greater after negative than after positive feedback, independent of the a priori probability of the outcome. No evidence for an increase in causal explanations after unexpected, as compared to expected, events was obtained. Several mediating processes are discussed.

The reported research was supported by grants Schw 278/2 and Str 264/2 from the Deutsche Forschungsgemeinschaft to Norbert Schwarz and Fritz Strack. Thanks are due to Bettina Scheuring, Annette Trilling and Michaela Wänke for their assistance in data collection and analysis. Address correspondence to: Gerd Bohner, Universität Mannheim, Sozialpsychologie, A 5, D-6800 Mannheim I, Federal Republic of Germany. 


\section{INTRODUCTION}

Most attribution theories share the basic assumption that individuals are motivated to attribute underlying reasons to perceived events (e.g. Heider, 1958; Kelley, 1973). This assumption is reflected in attribution research, which seems to imply that the attribution of causality is the predominant form of cognitive activity. The validity of this assumption, however, is disputed. Manis (1977), for example, questions the claim that persons are preoccupied with the search for causal explanations most of their time. If they are not, the conditions under which causal thinking occurs in everyday life need to be circumscribed in more detail.

In previous research, the determinants of causal reasoning have been investigated with various non-responsive methods, including the content analysis of written material or of subjects' free verbalizations in experimental simulations. In other studies, researchers tried to draw conclusions about the occurrence of causal reasoning from the observation of related cognitive processes, such as information search and memory (for a review see Weiner, 1985). The results of these studies consistently indicate that the extent of causal reasoning is determined by two factors (in addition to the less interesting case of explicit 'why'-questions), namely the expectedness of the event and its affective valence (Hastie, 1984; Weiner, 1985). Causal reasoning is more likely to be elicited by negative rather than positive, and by unexpected rather than expected events. Additive effects of both factors (where the highest degree of causal thinking is obtained after negative and unexpected events, and the lowest degree of causal reasoning after positive and expected events) as well as occasional interaction effects have been observed. Abele (1986), for example, found in an experimental simulation that negative valence increased the extent of causal reasoning especially for events of high probability, but less so for events of low probability.

Several processes may contribute to these findings. In the framework of schema theory (cf. Taylor and Crocker, 1981; Schwarz, 1985 for reviews), one might argue that events are understood to the extent that they are consistent with higher-order knowledge-structures (schemata). In such cases, a search for causal explanations seems to be unnecessary. Rather, a person should only engage in causal thinking if an event that he or she experiences is inconsistent with the available schemata. In this framework, unexpectedness of an event can be conceptualized as a special case of schema-inconsistency.

Similarly, Weiner (1985) assumes that unexpected events trigger some kind of cognitive orienting response. The deviation from a norm (e.g. an expectancy) needs to be explained, whereas events that are consistent with an expectancy have been frequently analysed in the past for their possible causes, so that the expense of attributional activities can be avoided.

In addition, negative events and their accompanying negative affective states may instigate causal reasoning because individuals are motivated to avoid unpleasant states (Weiner, 1985; Schwarz, 1987). To do so, they need adequate knowledge about the potential causes of negative events. Moreover, searching explanations for negative events may serve the purpose of reducing the aversive affect by finding external and self-irrelevant causes for the initially unpleasant event (Wyer and Carlston, 1979). Similarly, action identification theory (Wegner and Vallacher, 1986) predicts that persons who experience negative affect during or after completion of an action may consider the action in more detail at a lower level of abstraction (Vallacher and Wegner, 1987) and may think about possible reasons for the action's outcome. 
In addition, the process of causal reasoning itself may reduce the intensity of an emotion (Schwarz, 1987). Explaining why an event occurred promotes a dissociation of affect that has been experimentally demonstrated (e.g. Speisman, Lazarus, Mordkoff and Davison, 1964; Leyens, Cisneros and Hossay, 1976; Strack, Schwarz and Gschneidinger, 1985) as well as applied in various therapeutic approaches (Frank, 1982).

It must be taken into account, however, that an event's affective valence and subjective probability are usually confounded; that is, unpleasant events are less likely than pleasant events. Let us consider, for example, the outcome of an examination: Failing an exam is more unpleasant, but also occurs less often than passing an exam. This natural confounding of the two factors 'subjective probability' and 'affective valence' renders it difficult to isolate their relative impact on causal reasoning. Indirect evidence for the natural confounding of expectedness and valence is provided by a meta-analysis of mood studies that revealed that most respondents report being in a happy mood most of the time (Bless and Schwarz, 1984). This result suggests that events which elicit positive moods may appear to be the rule, whereas events which elicit negative feelings represent exceptions from the rule (Sommers, 1984; Schwarz and Clore, 1983; Schwarz, 1987).

This leads to an ambiguity in the interpretation of research findings that suggest mood-dependent increases or decreases of causal and analytic thinking (e.g. Isen, Means, Patrick and Nowicki, 1982; Abele, 1986): Do persons in a negative mood think more analytically, only because the event that made them feel sad was unexpected to them? Can bad moods and negative events, therefore, be conceptualized as subcategories of unexpected events, as Hastie (1984) proposed? Or is there a genuine impact of moods on causal thinking, independent of their expectedness?

This issue cannot be settled on the basis of the available empirical evidence, because in field studies, the natural confounding of the two variables has to be put up with, and in experimental simulations or role-plays, the mood-relevant events are produced by the subjects themselves. In order to disentangle the effects of the affective valence and subjective probability of an event on subsequent attributions, the two variables were independently manipulated in a $2 \times 2$-factorial laboratory experiment. Subjects were exposed to an event that was either pleasant or unpleasant, and either expected or unexpected. Affective valence was operationalized as success versus failure in an ability test, and high versus low expectancies were induced by presenting corresponding distributions of success and failure in a comparable population before the test was administered. The central dependent variable was the extent of causal reasoning after receiving the test result.

If subjective probability is the central determinant of causal attribution, unexpected events should always elicit explanations, and causal reasoning should increase after unexpected success as well as after unexpected failure. If, on the other hand, there is a genuine influence of an event's affective valence on causal attribution, failure should elicit more causal reasoning than success, over and above the effects of expectedness.

\section{METHOD}

\section{Subjects and procedure}

Forty-three students of the University of Mannheim were recruited as paid subjects for a study on the improvement of professional skills tests. The experiment was conducted 
in single sessions. Subjects were told that they would be administered 10 items of a professional skills test, and that after working on this task they were to answer various questions about the testing situation. The personal relevance of the task was enhanced by telling subjects that the test from which the items were taken was a valid predictor of professional success. The alleged 'professional skilis test' items were taken from the 'Standard' and 'Advanced Progressive Matrices' (Raven, 1958, 1962)'.

\section{Independent variables and manipulation check}

To assure that the task was well understood, the experimenter provided detailed explanations of two examples. Subsequently, subjects were informed that they could win a chocolate bar if they performed successfully. Success was defined as having solved at least seven of the 10 items. On a table in one corner of the laboratory, the subjects could see several chocolate bars, which had proved to be effective incentives in previous studies (Münkel, Strack and Schwarz, 1987). This additional reward was introduced to provide a salient mark of success, which would facilitate an expectancyindependent subjective definition of success.

To manipulate the expectancy of success, subjects were either informed that 77 per cent (high expectancy conditions) or 23 per cent (low expectancy conditions) of the previous student subjects had reached the criterion. Before subjects were administered the test items, the effectiveness of the expectancy manipulation was checked. The question read: 'Do you think that you will succeed in solving seven or more of the 10 items correctly?' The answer had to be given on a scale ranging from 1 ('no, certainly not') to 11 ('yes, quite certainly').

After completion of this manipulation check, the experimenter presented the 10 test items and made sure that subjects kept the time limit of 60 seconds per item. Subjects were forced to choose a response alternative within this time limit and were told that one may 'often guess the correct answer without being able to fully explain the solution principle. So please do make a choice on each item even if you are not certain about the correct solution'. This instruction was necessary to ascertain the credibility of the feedback.

When subjects had made their choices for all 10 items, the experimenter took the response sheet and went to a different table, ostensibly to check the test result. Up to this point, the experimenter was blind with respect to the success versus failure condition. Whether the subject would receive positive or negative feedback was determined by a card that the experimenter took from a pile invisible to the subjects. In the success condition, the subject was told that he or she had eight items correct, and the experimenter let him or her choose one of the chocolate bars. In the failure condition, the subject was informed that he or she had only four items correct and therefore had unfortunately failed to win a chocolate bar. The difficulty of the items and the time limit had been chosen so that the success as well as the failure feedback were highly credible. An informal interview at the end of the experiment revealed that only one subject was suspicious about the validity of the feedback. The data of this subject were excluded from the analysis.

\footnotetext{
'Item numbers (in the order of administration) in the failure conditions were: Advanced Progressive Matrices (APM) Set II: 24, 21, 17; Standard Progressive Matrices (SPM) Set E: 12; APM Set II: 28, 13, 16, 23, 26, 19. In the success conditions: APM Set II: 13, 14, 24; SPM Set E: 9; APM Set II: 17, 23, 26, 20, 16, 15.
} 
Before the dependent variables were assessed, the influence of the success versus failure feedback on subjects' affective state was assessed with the question: 'How do you feel at this very moment?' The response scale ranged from 1 ('very bad') to 11 ('very good').

\section{Dependent variables}

Subsequently, subjects were asked to answer a series of questions that were ostensibly designed to assess how he or she experienced the testing situation. All questions pertained to the extent and intensity of causal reasoning. The first two questions were phrased in an open-answer format. The first question pertained to the testing situation in general, the second one specifically to the test result. Finally, the intensity of causal reasoning was directly assessed in a closed response format. Thus, care was taken to present first open ended, non-responsive questions and to successively narrow the focus on the test result and finally on causal reasoning.

\section{Thought listings}

Subjects were first instructed to think about the testing situation and to write down everything that came to mind. They were provided a legal sized sheet with 18 lines for this task. There was no time limit. After this thought listing, subjects were instructed to think about their test result and to write down whatever came to mind about this aspect. In all other respects, the procedure was identical to the first thought listing. Thus, the focus was narrowed on result-related cognitions, but causal thinking was not yet explicitly mentioned.

After completion of the thought listings, subjects were instructed to read through each listing and to specify how many causal explanations of the test result it contained.

\section{Content analysis}

The interpretation of subjects' own counting of causal explanations is somewhat problematic, because subjects might not have produced any 'spontaneous' causal explanations but might rather have generated reasons after being questioned to check their thought listings, which may have caused them to re-interpret the listings in terms of causal explanations. Therefore, both thought listings were also content-analysed by two independent judges for the total number of words and sentences they contained, the number of causal explanations and the number of sentences mentioning positive or negative feelings ${ }^{2}$. The mean inter-rater correspondence for the number of causal explanations and the number of feelings mentioned was $r \square 0.65$ and $r=0.73$, respectively. For those cases about which the judges disagreed, the arithmetic mean of their ratings was computed for further analyses. A comparison of the total numbers of sentences and words that the judges had counted revealed perfect inter-judge correspondence.

\footnotetext{
${ }^{2}$ The following instruction was given to the judges: ' 1 . Count the number of sentences and the number of words on each thought listing. 2. Read the listing carefully and check the number of causal explanations for the test result it contains. 3 . Read the listing carefully and check the number of statements that express positive feelings (like joy, pleasure, relief, happiness, positive surprise etc.). 4. Read the listing carefully and check the number of statements that express negative feelings (like sadness, anger, depression, unhappiness, negative surprise etc.)'. Both judges analysed the whole corpus of response sheets.
} 


\section{Intensity judgments}

Finally, subjects were directly asked to rate the intensity of causal reasoning: 'How intensely did you think about the reasons for your test result?' The answers were to be reported on a scale ranging from 1 ('not intensely at all') to 11 ('very intensely').

\section{RESULTS}

\section{Manipulation checks}

As expected, the presentation of population norms affected the subjective probability to reach the criterion set by the experimenter. Subjects in the 'high expectancy' ( 77 per cent success) condition reported a higher expectancy of success $(M=7.3)$ than subjects in the 'low expectancy' (23 per cent success) condition $(M=5.9), t(40)=1.91, p<0.04$, one-tailed. To test the effectiveness of the manipulation of success and failure, the answers to the question, 'How do you feel at this very moment?', were subjected to a 2 (success versus failure) $\times 2$ (high versus low expectancy) factorial analysis of variance. This analysis revealed only a main effect of the 'success/failure' manipulation: As expected, subjects in the success conditions felt significantly better $(M=8.5)$ than subjects in the failure conditions $(M=7.1), F(1,38)=8.15, p<0.01$. The expectedness of the result did not affect subjects' affective state, $F<1$ for both the expectancy main effect and the two-way interaction.
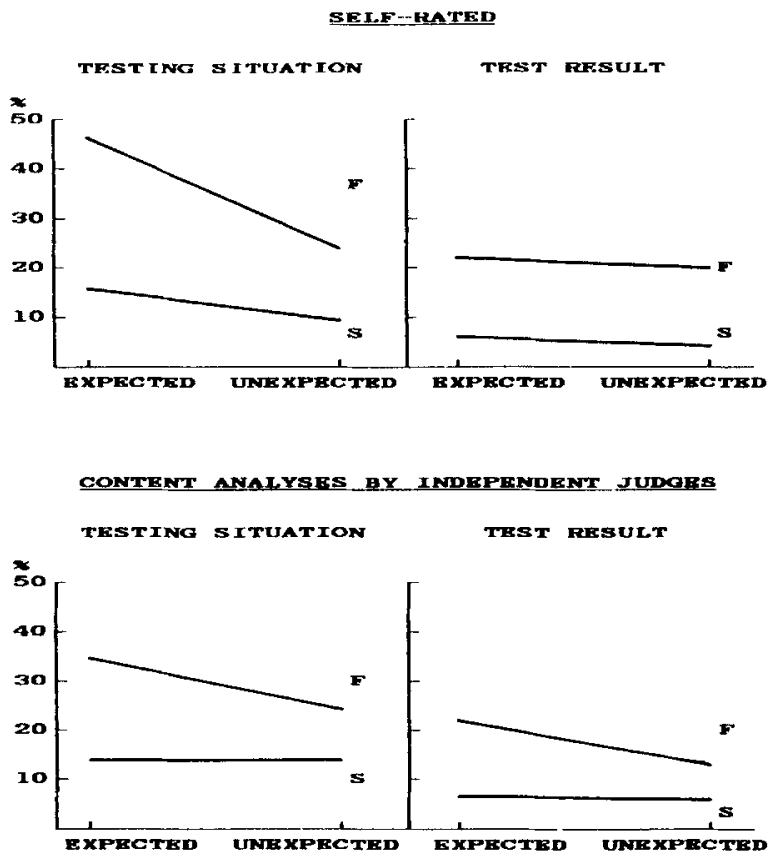

Figure 1. Mean percentages of causal attributions in subjects' cognitions about the testing situation (left) and the test result (right) as a function of valence and subjective probability: Subjects' self-ratings (above); results of content analysis (below). $S$ asuccess, $F$ a failure 
Thus, the manipulation checks revealed that the realization of different levels of subjective probability and affective valence was successful. It might be argued, however, that subjects in the failure conditions still scored above the scale midpoint on the question of affective state and thus felt reasonably well. On the other hand, there is evidence that even depressive subjects do not score far below the scale midpoint on questions of present mood (Bless, Bohner, Schwarz and Strack, 1988), which implies that there may be a general tendency to present oneself favourably on questions of this kind. Even if one is in doubt whether the failure condition induced categorically negative mood, there is a significant mood difference between success and failure conditions, so that subsequent results can be interpreted on the basis of a relative mood difference.

\section{Thought listings}

The percentages of causal explanations in relation to the total number of statements in the thought listings about the testing situation and the test result are shown in the upper part of Figure 1.

The 2 (success versus failure) $\times 2$ (high versus low expectancy) factorial analyses of variance revealed that subjects' reported thoughts about the testing situation as well as about the test result contained more causal explanations when the subjects had experienced a negative event (failure; $M$ 's $\square 35$ per cent and 21 per cent, respectively) than when they had experienced a positive event (success: $M$ 's $=12$ per cent and 5 per cent, respectively). The corresponding main effects of 'affective valence' are statistically significant for both thought listings, $F$ 's $(1,38)=7.38$ and $6.56, p$ 's $<0.02$.

In addition to this main effect, an unexpected statistical trend emerged in the first thought listing, pertaining to the testing situation in general: Subjects tended to generate more causal explanations after an expected ( $M=32$ per cent) than after an unexpected event ( $M=16$ per cent), $F(1,38)=3.11, p<0.09$. This surprising result may be due to the fact that, in the high expectancy conditions, the experimenter had already presented an 'explanation' by telling subjects the population norms. This explanation may have been easily accessible in these conditions and may have increased the number of causal explanations.

\section{Content analysis}

The results of the ratings of two independent judges, again subjected to 2 (success versus failure) $\times 2$ (high versus low expectancy) factorial analyses of variance, parallel the subjects' own ratings. The percentages of causal explanations are displayed in the lower part of Figure 1. In the judges' as well as the subjects' judgment, the negative event elicited more causal explanations ( $M=30$ per cent for thoughts on the testing situation, and $M=18$ per cent for thoughts on the test result) than the positive event ( $M=14$ per cent and 7 per cent, respectively), $F(1,37) \square 5.00^{3}, p<0.04$, and $F(1,38) \square$ $5.88, p<0.03$. No main effect for expectedness and no two-way interaction was obtained, all $p$ 's $>0.25$.

In the first thought listing, pertaining to the testing situation, the percentages of references to positive or negative feelings were unaffected by experimental conditions,

\footnotetext{
${ }^{3}$ One thought listing about the testing situation was unreadable, so there were only 41 valid cases for this part of the analysis.
} 
all $p$ 's $>0.15$. In the second thought listing, pertaining to the test result, main effects of affective valence were obtained. After success, subjects' thought listings contained more references to positive $(M=0.66)$ and fewer references to negative $(M=0.11)$ feelings than after failure $(M=0.05$ and $M \square 0.40$, respectively), $F(1,38)=20.58$, $p<0.0005$, and $F(1,38)=4.72, p<0.04$. No other main or interaction effects emerged, all $p$ 's $>0.15$. These results provide further evidence for a change of affective state in reaction to success and failure.

Finally, the number of sentences and words in both thought listings were unaffected by experimental conditions, all $p$ 's $>0.10$.

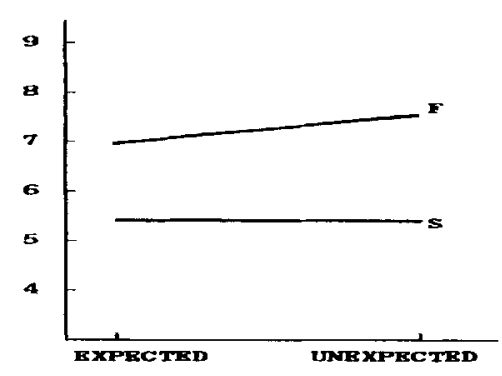

Figure 2. Subjects' mean ratings of intensity of causal reasoning as a function of valence and subjective probability (eleven-point scale ranging from 1 , 'not intensely at all', to 11 , 'very intensely'). $\mathrm{S}=$ success, $\mathrm{F}=$ failure

\section{Intensity of causal reasoning}

Subjects' self-ratings of the intensity of their causal reasoning are consistent with the results reported so far.

As can be seen in Figure 2, subjects in the failure conditions reported a greater intensity of causal reasoning $(M=7.3)$ than subjects in the success conditions ( $M=5.4$, $F(1,38)=4.39, p<0.05$. Again, no significant effect of subjective probability of the outcome emerged, all other $F<1$.

\section{DISCUSSION}

The reported results provide first experimental evidence for the hypothesis that the affective valence of an event and the resulting mood state can influence causal thinking, independently of the event's expectedness. Negative events lead to intensified causal reasoning in comparison to positive events of equal probability. The results of the manipulation checks clearly demonstrate that a confounding of subjective probability and affective valence could be avoided in the present study. Therefore, affective valence seems to be a predictor of causal attributions in its own right. Thus, the need to explain negative events is not merely a subcategory of the need to explain unexpected events.

On the other hand, no evidence for an increase in causal reasoning after unexpected events was obtained in the present study. One possible explanation for this unexpected 
finding is that the expectedness of the outcome was not as important to subjects as its affective valence in this particular situation. In different types of situations, the relative impact of expectancy and valence on causal reasoning may be quite variable. Nevertheless, the manipulation check revealed a significant difference in subjects' expectations between the high and low expectancy conditions, indicating the effectiveness of the present manipulation. Thus, it is safe to conclude that the observed effects of affective valence were independent of subjective probability, despite a successful variation of the latter variable.

Now that the influence of affective valence on causal reasoning has been demonstrated and disentangled from expectancy effects, the question arises, why persons in a negative mood are likely to generate more causal attributions than persons in a positive mood. In this regard, it is important to note parallel findings in other research areas that suggest pronounced influences of individuals' affective state on information processing. It has been demonstrated, for example, that positive mood, as compared to neutral mood, elicits simplified processing strategies and less systematic problem solving on complex judgmental tasks (Isen et al., 1982). Similarly, persons in a negative mood were found to elaborate the arguments of a persuasive communication systematically, whereas persons in a positive mood did not engage in systematic processing. Accordingly, subjects in a depressed mood were more persuaded by strong than by weak arguments, whereas subjects in an elated mood were equally affected by both types of arguments in their cognitive responses as well as in their attitude change (Bless et al., 1988; Worth and Mackie, 1987). There are, at least, three possible explanations for the increase in causal and analytic reasoning under the influence of negative events and the resulting negative feeling states.

First, an intensified search for causal explanations makes it more likely that external and self-irrelevant attributions for the event may be identified (Wyer and Carlston, 1979). Thereby the evaluation of the event and its consequences may change and the negative feelings associated with it may be reduced. Second, the increase of causal reasoning after a negative event may serve the purpose of preparing actions that are likely to eliminate the aversive state or to avoid similar events in the future. In order to actively eliminate or avoid certain situations, a person must have reasonably accurate knowledge about their causation, i.e., he or she needs to know what conditions are to be changed or avoided. A third explanation does not focus on the results of causal attributions, but on the process of causal reasoning itself. Causal thinking itself may reduce the intensity of affective states (e.g. Speisman et al., 1964; Schwarz, 1987). This hypothesis is supported by the finding that thinking about pleasant or unpleasant past life events leads to pronounced changes in affective states if it is vivid and concrete. If, on the other hand, thinking is focused on causal explanations for the event, changes in affect are not obtained (Strack et al., 1985, Experiment 3). Thus, causal thinking may serve for the control of emotion.

Obviously, these process assumptions are not mutually exclusive. Which one is most applicable, and how far the different mechanisms may be intertwined, cannot be decided on the basis of the available data and awaits clarification by further research. The purpose of the present study was to disentangle the natural confounding of affective valence and subjective probability in a controlled experiment. The results suggest that affective valence by itself should be taken into account as a determinant of causal attribution in its own right. 


\section{REFERENCES}

Abele, A. (1986, April). 'Erwartung und Valenz als Auslösebedingungen von Nachdenkprozessen'. 3rd Tagung der Arbeitsgruppe Sozialpsychologie, Erlangen, FRG.

Bless, H., Bohner, G., Schwarz, N. and Strack, F. (1988). 'Happy and mindless? Moods and the processing of persuasive communications'. Manuscript, submitted for publication.

Bless, H. and Schwarz, N. (1984, April). 'Ist schlechte Stimmung die Ausnahme? Eine Metaanalyse von Stimmungsuntersuchungen'. 26th Tagung experimentell arbeitender Psychologen, Nürnberg, FRG.

Frank, J. D. (1982). 'Therapeutic components shared by all psychotherapies'. In: Harvey, J. H. and Parks, M. M. (Eds) Psychotherapy Research and Behavior Change. The Master Lecture Series, Vol. I, APA, Washington.

Hastie, R. (1984). 'Causes and effects of causal attribution', Journal of Personality and Social Psychology, 46: 44-56.

Heider, F. (1958). The Psychology of Interpersonal Relations, Wiley, New York.

Isen, A. M., Means, B., Patrick, P. and Nowicki, G. (1982). 'Some factors influencing decisionmaking strategy and risk taking'. In: Clark, M. S. and Fiske, S. T. (Eds) Affect and Cognition, Erlbaum, Hillsdale, N.J.

Kelley, H. H. (1973). 'The process of causal attribution', American Psychologist, 28: 107-128.

Leyens, J., Cisneros, T. and Hossay, J. (1976). 'Decentration as a means for reducing aggression after exposure to violent stimuli', European Journal of Social Psychology, 6: 459-473.

Manis, M. (1977). 'Cognitive social psychology', Personality and Social Psychology Bulletin, 3: 550-566.

Münkel, T., Strack, F. and Schwarz, N. (1987, April). 'Der Einfluß der experimentellen Honorierung auf Stimmung und Wohlbefinden: Macht Schokolade glücklich?'. 29th Tagung experimentell arbeitender Psychologen, Aachen, FRG.

Raven, J. C. (1958). Standard Progressive Matrices. Sets A, B, C, D, and E, Lewis, London.

Raven, J. C. (1962). Advanced Progressive Matrices. Set II. 1962 Revision, Lewis, London.

Schwarz, N. (1985). 'Theorien konzeptgesteuerter Informationsverarbeitung'. In: Frey, D. and Irle, M. (Eds) Theorien der Sozialpsychologie, Vol. 3, Huber, Bern.

Schwarz, N. (1987). Stimmung als Information, Springer, Heidelberg.

Schwarz, N. and Clore, G. (1983). 'Mood, misattribution, and judgments of subjective wellbeing: Informative and directive functions of affective states', Journal of Personality and Social Psychology, 45: 513-523.

Sommers, S. (1984). 'Reported emotions and conventions and emotionality among college students', Journal of Personality and Social Psychology, 46: 207-215.

Speisman, J. C., Lazarus, R. S., Mordkoff, A. and Davison, L. (1964). 'Experimental reduction of stress based on ego-defense theory', Journal of Abnormal and Social Psychology, 68: $367-380$.

Strack, F., Schwarz, N. and Gschneidinger, E. (1985). 'Happiness and reminiscing: The role of time perspective, affect, and mode of thinking', Journal of Personality and Social Psychology, 49: 1460-1469.

Taylor, S. E. and Crocker, J. (1981). 'Schematic bases of social information processing'. In: Higgins, E. T., Herman, P. and Zanna, M. (Eds) Social Cognition: The Ontario Symposium, Erlbaum, Hillsdale, NJ.

Vallacher, R. R. and Wegner, D. M. (1987). 'What do people think they're doing? Action identification and human behavior', Psychological Review, 94: 3-15.

Wegner, D. M. and Vallacher, R. R. (1986). 'Action identification'. In: Sorrentino, R. M. and Higgins, E. T. (Eds) Handbook of Motivation and Cognition: Foundations of Social Behavior, Guilford, New York.

Weiner, B. (1985). "'Spontaneous" causal thinking', Psychological Bulletin, 97: 74-84.

Worth, L. T. and Mackie (1987). 'Cognitive mediation of positive affect in persuasion', Social Cognition, 5: 76-94.

Wyer, R. S. and Carlston, D. E. (1979). Social Cognition, Inference and Attribution, Erlbaum, Hillsdale, N.J. 


\section{RÉSUMÉ}

Qu'est ce qui élicite l'attribution causale: l'impact de la valence et des probabilités subjectives.

Plusieures études sur le terrain et des simulations expérimentales ont demontré que le raisonnement causal augmente après des événements inattendus aussi bien qu'après des événements désagréables. Cependant, des événements désagréables apparaissent moins probables dans la vie quotidienne que des événements agréables. De fait, la probabilité d'un événement et sa valeur hédonique étaient confondues de manière naturelle dans ces études. Pour isoler la contribution des deux facteurs, la probabilité subjective et la valence d'un événement étaient manipulées indépendamment dans une expérience de laboratoire. Les sujets ont répondu à un soi-disant 'test de savoir-faire professionel' et étaient informés de leur réussite ou de leur échec selon un critère établi par l'expérimentateur. La probabilité subjective de réussite a été manipulée en informant les sujets de la distribution des réussites et des échecs dans une population comparable (soit 23 per cent soit 77 per cent réussissaient le test). Les résultats indiquent un effet marqué de la valence: lorsque le sujet croyait avoir échoué, l'intensité du raisonnement causal était plus forte et les raisons avancées pour expliquer l'échec plus nombreuses que lorsque le sujet croyait avoir réussi, et cela indépendamment de la probabilité a priori de la réussite. Aucun effet du charactère attendu ou inattendu de l'événement sur l'explication causale a été trouvé. Plusieurs processus médiateurs sont discutés.

\section{ZUSAMMENFASSUNG}

In einer Reihe von Feldstudien und Simulationsexperimenten wurde gezeigt, daß sowohl erwartungsdiskrepante als auch negative Ereignisse das Ausmaß kausalen Nachdenkens erhöhen. Da im Alltag allerdings unangenehme Ereignisse für unwahrscheinlicher gehalten werden als angenehme, war somit die subjektive Wahrscheinlichkeit eines Ereignisses mit der durch die Valenz des Ereignisses ausgelösten Stimmung konfundiert. Um diese Konfundierung aufzulösen, wurden in einem Laborexperiment subjektive Erwartung und Valenz unabhängig voneinander variiert. Versuchspersonen bearbeiteten einen angeblichen Berufseignungstest und erhielten anschließend eine Erfolgs- oder Mißerfolgsrückmeldung, bezogen auf ein vom Versuchsleiter vorgegebenes Kriterium. Die subjektive Erfolgswahrscheinlichkeit wurde variiert, indem den Versuchspersonen die Verteilung von Erfolg und Mißerfolg in der Population mitgeteilt wurde ('23 Prozent vs. 77 Prozent der Teilnehmer erreichen das Kriterium'). Die Ergebnisse zeigen einen ausgeprägten Effekt der Valenz: Sowohl die Intensität des kausalen Nachdenkens als auch die Anzahl der Ursachen für das Ergebnis, über die die Versuchspersonen nachdenken, ist nach negativer Rückmeldung größer als nach positiver. Die vorliegende Untersuchung bietet keine Evidenz für eine Zunahme kausalen Nachdenkens nach unerwarteten Ereignissen. Verschiedene vermittelnde Prozesse werden diskutiert. 